\title{
BROAD PECTUS EXCAVATUM TREATMENT: LONG TERM RESULTS OF A BRAZILIAN TECHNIQUE
}

\section{TRATAMENTO DO PECTUS EXCAVATUM AMPLO: RESULTADOS A LONGO PRAZO DE UMA TÉCNICA BRASILEIRA}

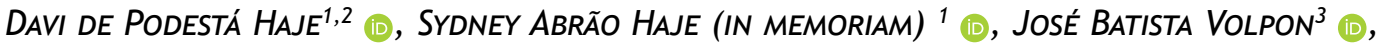 \\ ana Carolina Oliveira da Silva ${ }^{2}$ (1), Leonardo Ferreira Braz Lima ${ }^{2}$ (i), Wilson Huang ${ }^{2}$ (i) \\ 1. Centro Clínico Orthopectus, Brasília, DF, Brazil. \\ 2. Hospital de Base do Distrito Federal, Department of Orthopedic Surgery, Brasília, DF, Brazil \\ 3. University of São Paulo, School of Medicine of Ribeirão Preto, Department of Biomechanics, Medicine and Rehabilitation of the Locomotor System, Ribeirão Preto, SP, Brazil.
}

\section{ABSTRACT}

Objective: This study aims the treatment results of broad pectus excavatum after a long-term follow-up and skeletal maturity. Methods: Eighty-four children and adolescents with broad-type pectus excavatum were selected for evaluation after treatment with a dynamic orthosis that applies compression to the lower rib projections and prescription of exercises. The broad pectus excavatum was defined as a deformity that the depressed area was greater and covered the area above and below the nipple line. All patients were evaluated for more than 1 year after the end of treatment and skeletal maturity. Post-treatment results were categorized as mild, moderate and severe. Statistic correlations between results and deformity flexibility, deformity severity, and adherence to treatment were assessed. Results: The mean age at the beginning of treatment was 13.3 years, and the follow-up duration was 25.7 months after suspension of orthosis use. Forty-eight percent of patients showed good results. With regular use of orthoses and performance of exercises, this rate increased to $70 \%(p<0,001)$. Mild cases showed more success than severe cases $(p=0,007)$. Initial flexibility didn't influence the results $(p=0,63)$. Conclusion: Treatment of broad pectus excavatum with orthoses and exercises led to good definitive results in most resilient patients, especially in those with mild deformities. Level of Evidence V, Expert Opinion.

Keywords: Braces. Funnel Chest. Pectus Excavatum. Orthotic Devices. Thoracic Wall.

\section{RESUMO}

Objetivo: Estudar os resultados de longo prazo e com seguimento até a maturidade esquelética do tratamento do pectus excavatum amplo. Métodos: 84 crianças e adolescentes foram tratados com uma órtese que aplicacompressão nas saliências costais inferiores, associada a exercícios específicos. A deformidade foi classificada como ampla quando a depressão tem maior extensão e abrange uma área acima e abaixo da linha mamilar. Os resultados foram categorizados em ruim, regular ou bom, sendo correlacionados estatisticamente com a flexibilidade, a gravidade da deformidade e a adesão ao tratamento, com avaliação um ano após o fim do tratamento e na maturidade esquelética. Resultados: A idade média no início do tratamento foi de 13,7 anos e o seguimento médio foi de 25.7 meses após a suspensão do uso da órtese. $48 \%$ dos casos apresentaram sucesso com o tratamento, mas quando os exercícios e o uso da órtese foram regulares, esta taxa aumentou para $70 \%(p<0,001)$. Os casos mais leves tiveram maior sucesso que os de maior gravidade $(p=0,007)$, mas a flexibilidade inicial não influenciou os resultados ( $p=0,63)$. Conclusão: O tratamento do pectus excavatum amplo com o uso de órtese e exercícios apresentou bons resultados definitivos na maioria dos pacientes resilientes, em especial nos casos mais leves. Nível de Evidência V, Opinião do Especialista.

Descritores: Braquetes. Tórax em Funil. Pectus Excavatum. Aparelhos Ortopédicos. Parede Torácica.

Citation: Haje DP, Haje AS, Volpon JB, Silva ACO, Lima LFB, Huang W. Broad pectus excavatum treatment: long term results of a brazilian technique. Acta Ortop Bras. [online]. 2021;29(4):197-202. Available from URL: http://www.scielo.br/aob.

\section{INTRODUCTION}

In pectus excavatum, we can observe an area of depression that can be localized or broad, symmetrical or asymmetrical and may be associated with varying degrees of lower costal arch protrusions. ${ }^{1-3}$ The most common reasons that patient or family members opt for treatment of these deformities are embarrassment and body-image issues. ${ }^{4}$ Severe pectus excavatum deformities may be associated with exercise intolerance and shortness of breath. ${ }^{5}$

The most widely used treatment for pectus excavatum is surgery. ${ }^{6}$ Another option is non-invasive treatment with use of a brace and performance of specific physical exercises. This technique was initially described by Haje in $1979,{ }^{7}$ followed by reports of good results in a large percentage of patients with pectus carinatum. ${ }^{8,9}$

All authors declare no potential conflict of interest related to this article.

The study was conducted at Centro Clínico Orthopectus, DF, Brazil

Correspondence: Davi P. Haje. SMHN 2 Bloco A, Ed. Clínicas, sala 804-806, Brasília, DF, Brazil. 70710904. davihaje@yahoo.com.br

Article received on 09/10/2020, approved on 11/05/2020. 
Intuitively, constant pressure on the anomalous protrusion can lead to bone remodeling and permanent correction of the deformity. Although much less is known about brace use for the treatment of pectus excavatum. In this case, the orthosis has a compressive effect on the protrusion of the last ribs by lowering them, indirectly causing bone depression elevation with the performance of specific exercises. This technique was developed by Haje et al. . $^{1-3,9,10}$ who reported that the application of a standardized treatment protocol is an important factor for achieving good results, especially in more flexible cases. ${ }^{1,9,10}$ But previous Haje's studies did not describe the brace and exercise treatment long term results for pectus. It is important to follow patients with musculoskeletal deformities (like clubfoot, pectus and others) treated in conservative or surgically ways until their growth period ends because it is possible to have relapses and the final result may change..$^{6,11}$

In addition to this orthosis, reports describes non-surgical treatment of pectus excavatum using a device called the Vacuum Bell ${ }^{\circledR} ; 12$ use of the dynamic chest compressor (DCCII) is associated with Vacuum Bell. ${ }^{1,13}$

This study targets the assess long-term results of a non-invasive method for correction of broad-type pectus excavatum using the method described by Haje, ${ }^{9}$ involving a special orthosis for use with specific physical exercises.

\section{MATERIALS AND METHODS}

Patients were treated between 1977 and 2017 according to a pre-established protocol and supervised by one of the authors (DPH or $\mathrm{SAH}$ ). Overall, 573 patients with broad-type pectus excavatum were identified. We excluded 141 untreated patients (105 with non-indications for treatment and 36 patients who did not consent to therapy), those with follow-up of less than one year $(n=125)$, those with an iatrogenic etiology $(n=2)$, those who had used a vacuum bell $(n=14)$, and those who ceased treatment $(n=31)$. Patients who did not attend a follow-up after 1 year of treatment completion and at skeletal maturity were also excluded ( $n=176)$ because the study objective was not to verify the immediate or short term results. Only patients who were followed-up for more than 36 months and 12 months after they had finished growing were included, totalizing 84 patients.

Pectus excavatum was classified as broad when the deformity was greater and covered an area above and below the nipple line (Figure 1). 1,2,3 The other form of pectus excavatum is localized and will be evaluated in another publication.

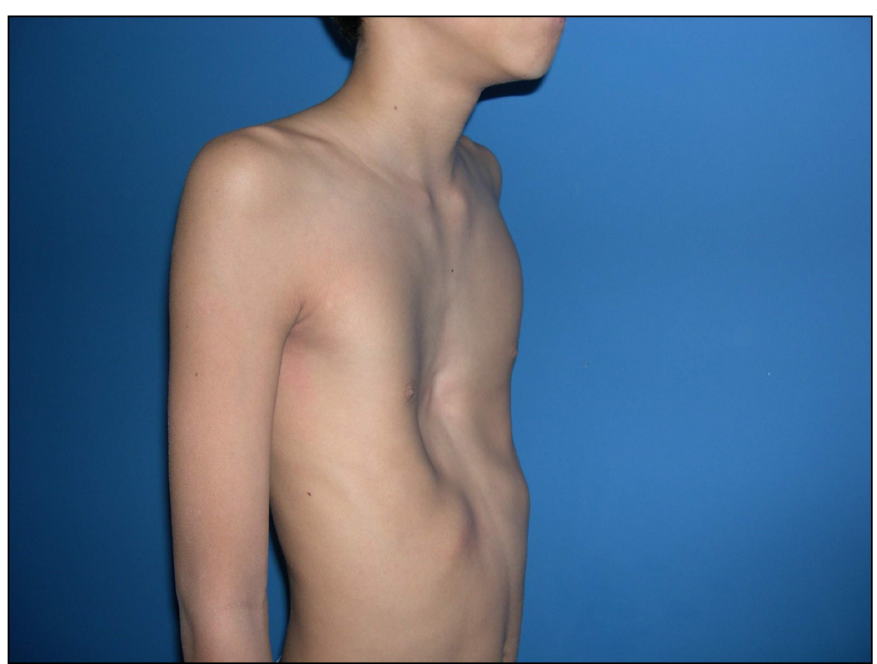

Figure 1. Broad-type pectus excavatum. The area of deformity is extensive and often presents with changes to the lower coastal arch cage which compromises aesthetics.
The deformities were classified as mild, moderate, or severe based on clinical findings and as determined by the physician (Figure 2). The flexibility of the deformity was evaluated using a manual compression maneuver of the lower rib cage in the anteroposterior direction performed by the examiner. Simultaneously, patients were asked to perform the Valsalva maneuver together with adduction against upper limb resistance. Younger patients were requested to blow a balloon. The effect of this maneuver on the excavatum was observed. The deformity was classified as "flexible" when there was complete reversal of the depression, "rigid or poorly flexible" when the depression did not change or changed slightly, and "moderately flexible" with partial correction (Figure 3). ${ }^{9}$ Physical examination was performed only by the first or second author.

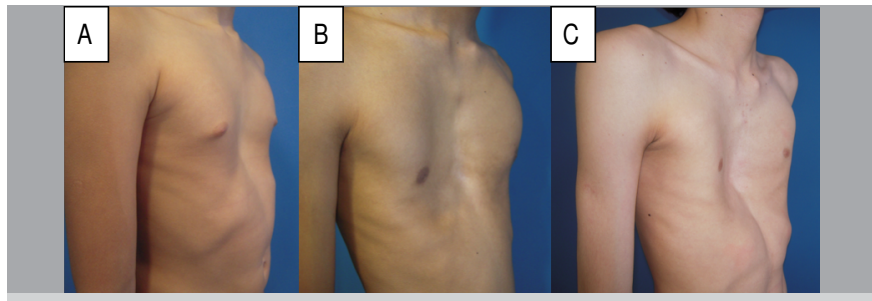

Figure 2. Classification of the severity of broad-type pectus excavatum, according to aesthetic impairment. (A) Mild; (B) Moderate; (C) Severe.

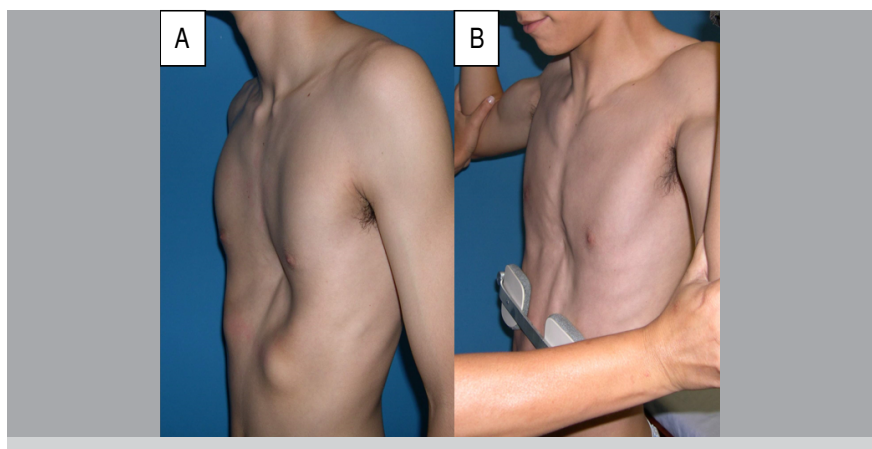

Figure 3. (A) Flexibility test for pectus excavatum; (B) with compression of the lower rib cage, in this case performed by the dynamic chest compressor itself.

Treatment was indicated for moderate or severe deformities in children and adolescents. Treatment was indicated in some mild cases when the pectus was noteworthy to the adolescent and accepted by the family. We indicated treatment before puberty especially if the deformity started getting worse. Adolescents with hyperkyphosis were encouraged to start treatment. Patients with mild scoliosis (less than $20^{\circ}$ curvature as determined using the Cobb radiographic method) associated with the pectus (regardless of its severity) were also encouraged to start treatment. Only growing individuals with personal and family motivation and acceptance were treated.

The orthosis is shown in Figure 4. Patients were instructed to wear the orthosis 23 hours per day (minimum 18 hours). Removal was allowed during the day for aquatic activities and contact sports. The compression force was controlled by the patient and maintained at a comfortable level. Progressive compressive adjustment was interrupted when the costal salience disappeared. Along with the use of the orthosis, specific exercises were recommended to strengthen the muscles of the anterior chest wall. Weaning from the orthosis was performed gradually until the minimum usage period of 24 months was completed. 


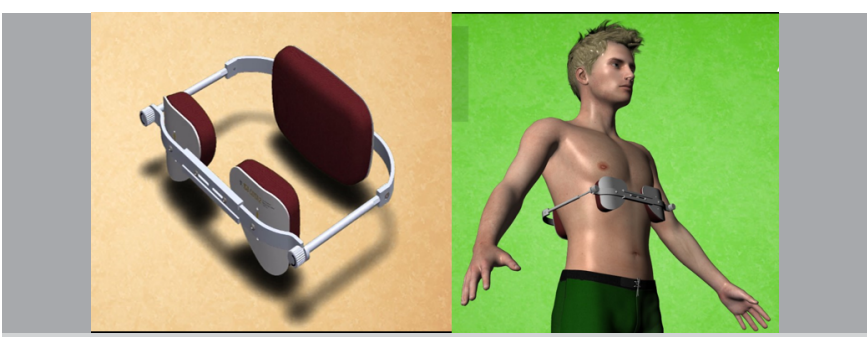

Figure 4. Type of brace used for the treatment of broad-type pectus excavatum. The two anterior cushions exert pressure on the last costal arches and are connected to a posterior cushion by means of a threaded bar that serves to control the compression force.

Adherence to treatment was classified as irregular when the orthosis was not used for the prescribed time, or no regular performance of the physical exercises. Patients who ceased orthosis use before discharge were excluded; but those who only ceased performing the exercises before the recommended period were classified as showing irregular adherence. Results were considered poor when the deformity did not change or worsened, average when there was under-correction, and good when there was significant improvement. The treatment results were analysed by either the first or second author of this manuscript. Treatment satisfaction was reported by the family (when the patient was a child) or by the adolescent patient as "satisfied" or "not satisfied". Treatment success was defined as a good result and if the patient was satisfied. All patients were photographed in the same positions, before and after treatment, and clinical images were used in the evaluation. The comparative group consisted of individuals who met indication for treatment but refused and then returned for re-evaluation.

The evaluation protocol was approved by our Institutional Ethics Committee (58417516.3.0000.5553).

\section{Statistical analysis}

The chi-square test $\left(\chi^{2}\right)$ was used in the analysis of categorical variables and also Cochran-Mantel-Haenszeltest to determine whether the odds ratios between two variables remained the same for categories of a third variable. The level of significance was $p \leq 0.05$. The Statistical Package for Social Sciences (SPSS) v.22.0 (IBM Corp., Armonk, NY, USA) was used for all statistical analyses.

\section{RESULTS}

The mean age at the beginning of treatment was 13.3 years (standard deviation $[S D]=3.5$ years; median $=13,0$ years, variation $4,8-17,8$, being 19\% $(n=16)$ less than 10 years old. The age histogram of the 84 treated patients that completed the follow-up is shown in Figure 5. Of the treated patients, 66 (79\%) were male and 18 (21\%) were female. The mean follow-up duration was 25.7 months after the end of treatment.

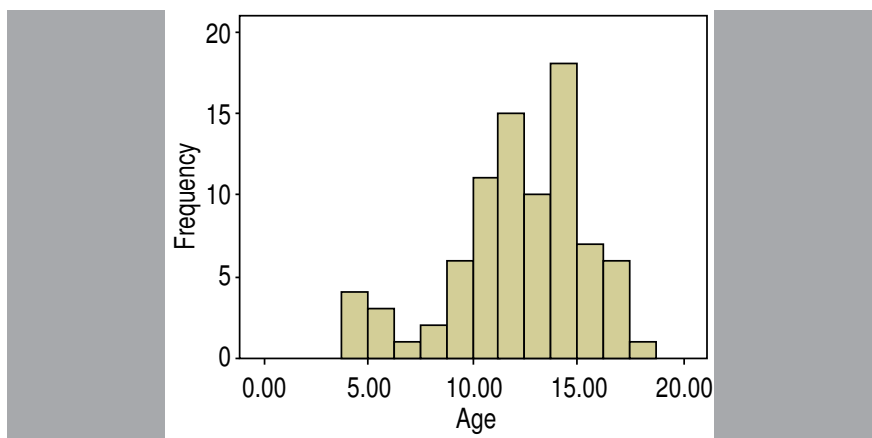

Figure 5. The histogram of age of the treated patients that completed the follow-up.

Eleven patients (13\%) presented with mild initial deformity, $55(66 \%)$ were moderate, and 18 (21\%) were severe. The deformities were very flexible or moderately flexible in 50 patients (59\%) and were rigid or not very flexible in 34 patients (41\%).

Results were considered good in 40 patients (48\%), average in 36 patients (43\%), and poor in eight patients (9\%). Figures 6 and 7 show a good result. Treatment satisfaction was reported in all patients with good results, in $20 \%(n=17)$ of those with average results and in none with poor results.

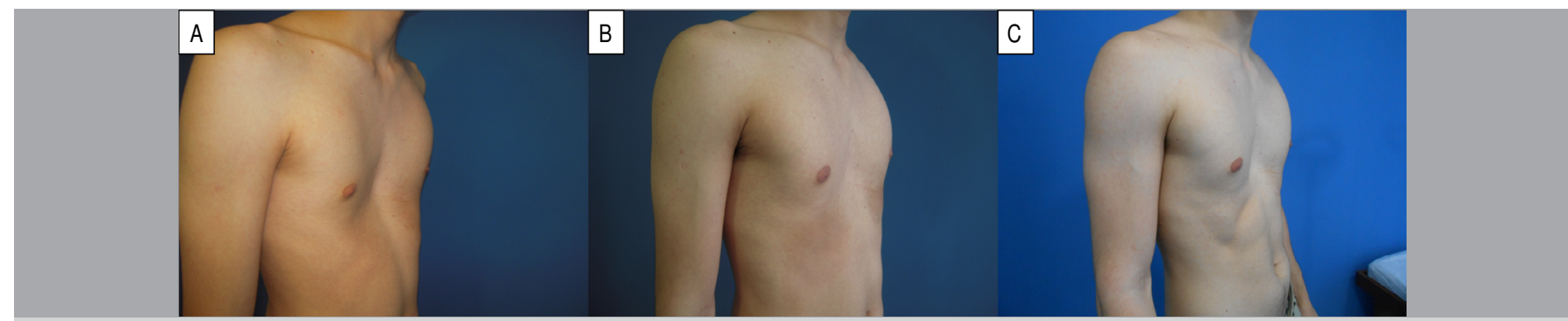

Figure 6. A patient aged 15 years and 6 months at the beginning of treatment (A), with good results obtained less than 12 months after the beginning of treatment and maintained improvements after 28 months of follow-up (B), with maintenance of correction at 23 years-of-age, with 9 years of follow-up, and 5 years after complete interruption of treatment $(C)$.

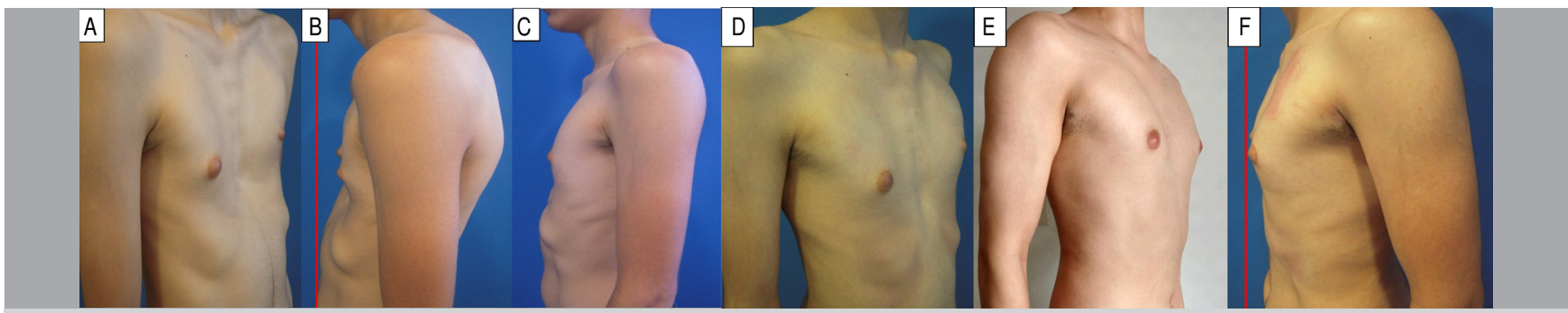

Figure 7. (A) A patient aged 13 years and 6 months showing pectus excavatum and hyperkyphosis (B_with natural posture; (C) and with posture corrected by the examiner, (D) with a good result after 3 months of treatment, which was maintained regularly until 15 years and 6 months of age, when orthoses weaning started, (E) with results maintained after 6 years of follow-up, and after 3 years of treatment interruption. He presented with correction of hyperkyphosis and protrusion of the lower ribs (see improvement of the positioning of the red line before treatment in $\mathrm{B}$ and $\mathrm{C}$, and at treatment end in $\mathrm{F}$ ). 
Good results were achieved in $72 \%(n=8)$ with mild deformities, $47 \%(n=26)$ with moderate deformities, and 33\% $(n=6)$ with severe deformities. Mild cases showed more success than severe cases $(p=0,007)$.

Regarding flexibility, the results were good in $48 \%(n=24)$ with flexible or moderately flexible deformities and $47 \%(n=16)$ with rigid or less flexible deformities.

The use of brace was regular in $69 \%(n=58)$ and irregular in $31 \%(n=26)$. Overall, $54 \%(n=45)$ of patients performed the specific exercises regularly, while $46 \%(n=39)$ performed these irregularly. When flexibility was analyzed in isolation, no significant differences is shown among the various results $(p=0,63)$. Even when flexibility was analyzed together with the regularity of the use of the orthosis and performance of the exercises, there was no significant influence on the response to treatment $(p=0,67)$.

Seventy percent of patients with regular orthosis use and exercise performance achieved good results ( $p<0,001)$. By contrast, when orthosis use was irregular, regardless of the regular performance of the exercises, only $29 \%$ of patients achieved good results $(p=0,84)$. Table 1 shows the associations between variables.

Table 1. Comparisons made and interpretation of results

\begin{tabular}{|c|c|c|}
\hline Comparison & $\begin{array}{c}\chi^{2} \text { value / P / } \\
\text { odds ratio } \\
\text { and C.I.95\% }\end{array}$ & $\begin{array}{c}\text { Association } \\
\text { between variables }\end{array}$ \\
\hline $\begin{array}{l}\text { Good results vs. } \\
\text { pectus severity }\end{array}$ & $\begin{array}{c}16,3 / p=0,007 / \\
3,8(1,1-13,4)\end{array}$ & Negative \\
\hline $\begin{array}{l}\text { Good results vs. } \\
\text { pectus flexibility }\end{array}$ & $\begin{array}{l}0,23 / p=0,63 / \\
0,84(0,42-1,7)\end{array}$ & No correlation \\
\hline $\begin{array}{l}\text { Good results vs. regular } \\
\text { orthotic wearing }\end{array}$ & $\begin{array}{c}24,68 / p<0,001 / \\
10,65(1,74-17,9)\end{array}$ & Positive \\
\hline $\begin{array}{l}\text { Good results vs. regular } \\
\text { physical exercises }\end{array}$ & $\begin{array}{l}8,57 / p=0,04 / \\
4,36(2,4-8,89)\end{array}$ & Positive \\
\hline $\begin{array}{l}\text { Good results vs. regular } \\
\text { orthotic wearing and } \\
\text { regular physical exercises }\end{array}$ & $\begin{array}{l}15,68 / p<0,001 / \\
5,22(2,15-12,64)\end{array}$ & Positive \\
\hline $\begin{array}{l}\text { Good results vs. irregular } \\
\text { brace wearing and regular } \\
\text { physical exercises }\end{array}$ & $\begin{array}{l}3,35 / p=0,84 / \\
1,22(0,38-3,27)\end{array}$ & No correlation \\
\hline
\end{tabular}

No major complications were observed; but skin irritation or transient hyperpigmentation occurred in the areas of pressure in about $4 \%$ of patients. In $12 \%$ of patients, was identified discomfort or transient pain in the orthosis support areas, both of which resolved with partial release of pressure. These complications did not lead to an interruption in orthosis use. Relapses in those patients that completed the follow-up were not showed.

Thirty-six patients or family members did not accept treatment; however, nine returned to be re-evaluated. Seven of these (78\%) presented worsening of the deformity (Figure 8) and two were stable. All patients with worsening of deformity presented with moderate or marked deformities, with four (57\%) defined as moderately flexible and three (43\%) defined as rigid at the last evaluation (approximately 15.2 years of age). Some treated patients who presented with some improvement returned with recurrence of the deformity when they stopped the treatment before medical orientation ( $n=5)$ (Figure 9).

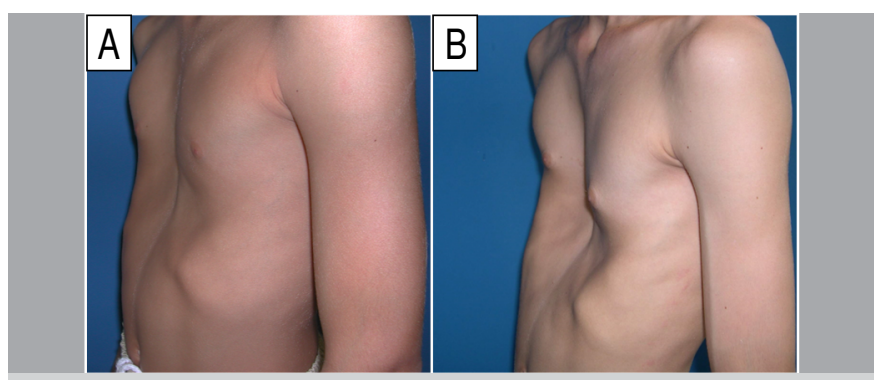

Figure 8. (A) A 10-year-old boy with moderate deformity, where the family did not accept the indication for treatment. (B) At 14 years-ofage, the deformity is worse $(B)$.

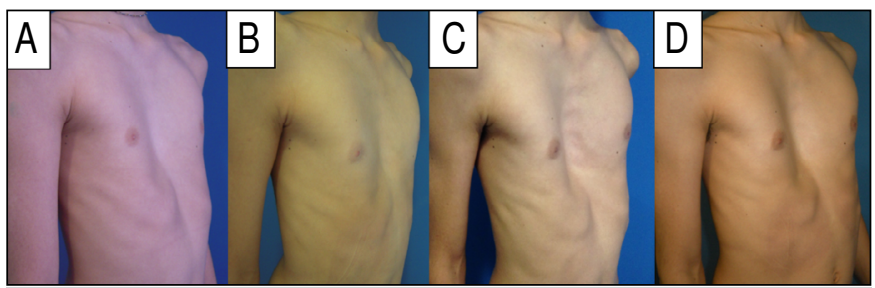

Figure 9. (A)The patient started treatment at 12 years of age; (B) with good results after 12 months of regular orthosis use and irregular exercise adherence. (C) Besides, the patient abandoned treatment. In adolescence, the deformity recurred, and treatment was restarted. (D) After 1 year, there was some improvement.

In two patients, a slight hypercorrection (depressed area turned into a pectus carinatum) was presented and managed by reducing the orthosis DCC II usage time or the use of a second orthosis for the treatment of pectus carinatum, called DCC I (Figure 10).

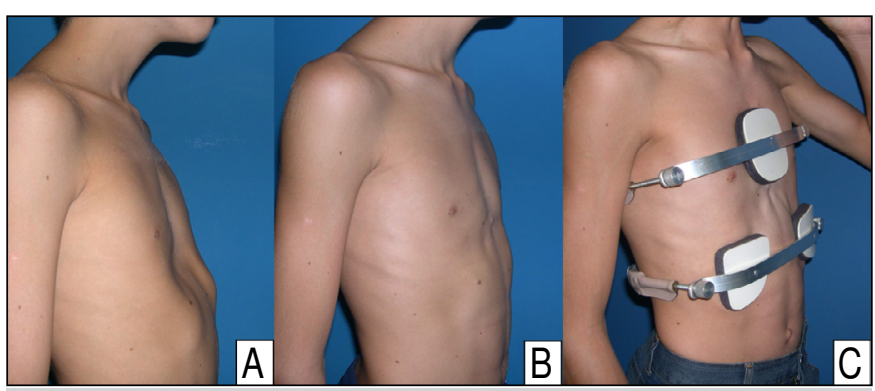

Figure 10. (A) An 11-year-old boy with moderate excavatum deformity who presented with hypercorrection; (B) after 24 months of treatment with development of mild pectus carinatum; (C) that was controlled using another orthosis.

\section{DISCUSSION}

In terms of treatment, surgical correction of pectus is considered by most surgeons as the only effective option. The aesthetic results of surgery are not always the desired ones; for example, the possibility of maintaining prominent costal edges and the possible appearance of a reactive pectus carinatum is accepted. ${ }^{14}$ Still, surgery poses serious complications, and life-threatening complications are often underestimated, including subsequent removal of the implant. ${ }^{15}$ This makes the decision to proceed with surgical treatment very difficult for some patients, especially those with mild or moderate pectus.

When choosing initial pectus treatment for growing patients, we recommend first considering non-invasive treatment methods such as those based on orthosis use (bracing) and physical exercises, as a low-risk method with the possibility of interruption in cases of 
intolerance or change of opinion is possible. Failure to recommend treatment in cases of skeletally immature pectus excavatum may constitute negligence because the patient's condition may worsen during their growth and because milder deformities showed better. In our opinion, surgery should be indicated for patients who cannot adapt or did not show good results with the available conservative therapy, as well as those who have severe deformities and psychological issues. Finally, the patient and their family must accept the risks imposed by surgical treatment.

$48 \%$ of the patients, had good results, suggesting that the broad form of pectus excavatum can be efficiently corrected using the non-invasive method described here as a group of patients followed skeletal maturity. Haje and Haje (2009), ${ }^{3}$ who treated localized and broad pectus excavatum with a brace and exercises, reported good results in $29 \%$ and $21 \%$ of patients after a follow-up of less than 1 year, respectively. Moon et al. ${ }^{16}$ reported that their results were long-term; despite, they accepted a minimum follow-up of only 13 months in cases of pectus carinatum treated with orthosis; we believe that a longer observation period to growth stabilization and an additional observation period after finishing treatment are essential.

In pectus excavatum, the pressure exerted by the orthosis on the lower anterior costal arches associated with exercises probably increased the pressure in the mediastinum with consequent expansion of the osteo-cartilaginous structures of the chest's anterior face, modifying the forces that act on the various growth plates and contributing to the remodeling of deformed structures. Wolff's law ${ }^{17}$ explains the remodeling process of skeletal structures. Wong and Carter reported that mechanical forces on the sternum may influence skeletal morphogenesis. ${ }^{18}$ In PE (pectus excavatum) patients, who reportedly have increased midline excursion at the umbilicus level, ${ }^{19}$ the braces and specific exercises might help limit that excursion. The action of the diaphragm may become more efficient to expand the chest as the protrusions of the costal edges are corrected by presence of the orthosis. The performance of specific and repetitive exercises associated with orthosis use, along with holding the maximum inspiration during muscle contraction, works actively to correct the depressed area of the pectus and stimulates postural improvement.
This study highlights some prognostic factors that are very useful during the initial treatment period. A positive correlation between good results and treatment adherence is observed, including regular orthosis use and regular performance of the associated exercises. We believe that pectus excavatum treatment with the use of orthoses and exercises should begin fast because we found that more severe deformities were related to worse results. Despite that, the correlation between flexibility and good results is not showed. Haje et al. ${ }^{1,3}$ found that flexibility was an important prognostic factor in the treatment with orthoses and specific exercises.

The method used in this study had a low rate of complications. The most frequent complication was skin irritation, which did not lead to treatment interruption.1,3 The other rare complication, hypercorrection, ${ }^{10}$ was very well managed with treatment adjustment and use of an orthosis used for reactive pectus carinatum.

Some limitations were shown in this study, most of which were based on subjective criteria used to define pectus type, its severity and flexibility. This limitation could be minimized with image evaluation methods that do not involve exposure to radiation, such as 3D structured light scanners, ${ }^{20}$ but this exam was not currently available The authors were concerned about using a CT before and after treatment because of radiation, costs and that would not change the braces and treatment indication criteria. Besides, the description of an objective flexibility test for pectus excavatum was not identified. The authors think that analyze results using photos in the same position before and after treatment is enough. The fact that all patients classified as a good result by the authors had satisfaction with their final result, brings more credibility to the treatment results.

\section{CONCLUSION}

In conclusion, we found that the non-invasive method for broadtype pectus excavatum correction presents good results in the patients followed until skeletal maturity and those who adhered to the treatment protocol, although it is a long treatment process that may lead to short or late loss of follow-up, treatment irregularity, or abandonment of treatment before the deformity is stabilized.

AUTHORS' CONTRIBUTIONS: Each author contributed individually and significantly to the development of this article. DPH: conceived and planned the activities that led to the study, participated in the review process, performed the treatment together with Sydney Haje from 1999 to July 22th 2011, and by himself since this last date, interpreted the results of the study and approved the final version; SAH (in memoriam): Performed the treatment from 1988 to July 22th 2011 (3 days before he passed away); JBV manuscript preparation, participated in the review process and approved the final version; ACOS: data collection and approved the final version; LFBL: data collection and approved the final version; WH: data collection and approved the final version.

\section{REFERENCES}

1. Haje SA, Haje DP, Silva M. Chest and shoulder girdle. In: Herbert S, Barros Filho TEP, Xavier R, Pardini Júnior AG, editors. Orthopedics and traumatology: principles and practices. 5th ed. Porto Alegre: Artmed; 2017. p. 81-100.

2. Haje SA. Pectus deformities: new concepts and orthopedic approach in children and adolescents - 1st part. Rev Bras Ortop. 1995;30(1/2):75-9.

3. Haje SA, Haje DP. An orthopaedic approach of the pectus deformity: 32 years of studies. Rev Bras Ortop. 2009;44(3):193-200.

4. Steinmann C, Krille S, Mueller A, Weber P, Reingruber B, Martin A. Pectus excavatum and pectus carinatum patients suffer from lower quality of life and impaired body image: a control group comparison of psychological characteristics prior to surgical correction. Eur J Cardiothorac Surg. 2011;40(5):1138-45.

5. Chao CJ, Jaroszewski DE, Kumar PN, Ewais MM, Appleton CP, Mookadam $F$, et al. Surgical repair of pectus excavatum relieves right heart chamber compression and improves cardiac output in adult patients--an intraoperative transesophageal echocardiographic study. Am J Surg. 2015;210(6):1118-25.

6. Nuss D, Obermeyer RJ, Kelly RE Jr. Pectus excavatum from a pediatric surgeon's perspective. Ann Cardiothorac Surg. 2016;5(5):493-500.
7. Haje SA, Raymundo JLP. Considerations on the deformities of the anterior thoracic wall and presentation of a non-invasive treatment for the protusion forms. Rev Bras Ortop. 1979;14(4):167-78.

8. Cohee AS, Lin JR, Frantz FW, Kelly RE Jr. Staged management of pectus carinatum. J Pediatr Surg. 2013;48(2):315-20.

9. Haje SA, Bowen JR. Preliminary results of orthotic treatment of pectus deformities in children and adolescents. J Pediatric Orthop. 1992;12(6):795-800.

10. Haje SA, Haje DP. Overcorrection during treatment of pectus deformities with DCC orthoses: experience in 17 cases. Int Orthop. 2006;30(4):262-7.

11. Luckett MR, Hosseinzadeh P, Ashley PA, Muchow RD, Talwalkar VR, Iwinski $\mathrm{HJ}$, et al. Factors predictive of second recurrence in clubfeet treated by ponseti casting. J Pediatr Orthop. 2015;35(3):303-6.

12. Haecker FM. The vacuum bell for conservative treatment of pectus excavatum: the Basle experience. Pediatr Surg Int. 2011;27(6):623-7.

13. Haje DP. Association of braces and exercises to vacuum bell for the treatment of pectus excavatum. J Pediatr Surg Spec. 2015;9:23.

14. Swanson JW, Colombani PM. Reactive pectus carinatum in patients treated for pectus excavatum. J Pediatr Surg. 2008;43(8):1468-73. 
15. Hebra A. Minor and major complications related to minimally invasive repair of pectus excavatum. Eur J Pediatr Surg. 2018;28(4):320-6.

16. Moon DH, Kang MK, Lee HS, Lee S. Long-term results of compressive brace therapy for pectus carinatum. Thorac Cardiovasc Surg. 2019;67(1):67-72.

17. Wolff $J$. The law of bone remodeling. Berlin: Springer; 1986.

18. Wong M, Carter DR. Mechanical stress and morphogenetic endochondral ossification of the sternum. J Bone Joint Surg Am. 1988;70(7):992-1000.
19. Redlinger RE Jr, Kelly RE, Nuss D, Goretsky M, Kuhn MA, Sullivan K, et al. Regional chest wall motion dysfunction in patients with pectus excavatum demonstrated via optoelectronic plethysmography. J Pediatr Surg. 2011;46(6):1172-6.

20. Uccheddu F, Ghionzoli M, Volpe Y, Servi M, Furferi R, Governi L, et al. A novel objective approach to the external measurement of pectus excavatum severity by means of an optical device. Ann Thorac Surg. 2018;106(1):221-7. 